MOBILE LEARNING ANYTIME, ANYWHERE: WHAT ARE OUR STUDENTS DOING?

\author{
Angela Murphy \\ Australian Digital Futures Institute \\ University of Southern Queensland \\ Toowoomba, Australia \\ angela.murphy@usq.edu.au
}

\title{
Helen Farley
}

Australian Digital Futures Institute

University of Southern Queensland

Toowoomba, Australia

helen.farley@usq.edu.au

Michael Lane

School of Management and Enterprise

University of Southern Queensland

Toowoomba, Australia

michael.lane@usq.edu.au

\author{
Abdul Hafeez-Baig \\ School of Management and Enterprise \\ University of Southern Queensland \\ Toowoomba, Australia \\ abdul.hafeez-baig@usq.edu.au
}

\section{Brad Carter}

School of Agricultural, Computational and Environmental Sciences

University of Southern Queensland

Toowoomba, Australia

brad.carter@usq.edu.au

\begin{abstract}
Recent developments in mobile technologies have provided unique opportunities for learning and teaching. This paper reports on recent research undertaken at a regional Australian university in order to understand how higher education students are using mobile devices to support their learning. A survey instrument was developed and deployed and the data collected analysed quantitatively. Upon analysis, these data demonstrate that students are predominantly using laptop computers to support their learning, but their use of smart phones and tablets are also used for a number of specific learning activities. Further analysis indicates that in spite of the limitations in the formal university infrastructure, many students would like to use their mobile devices for formal learning as well as informal learning.
\end{abstract}

Keywords: Mobile learning, m-learning, smart technologies, student usage, higher education

\section{INTRODUCTION}

Recent research suggests that mobile technologies offer unique opportunities for students to become more engaged with learning activities beyond the boundaries of the learning management system 
(Matias \& Wolf, 2013). The functionality of these devices is continuously enhanced through the inclusion of features from established technologies such as Personal Digital Assistants (PDA), portable media players, GPS navigation, digital cameras and eBook readers (Alley \& Gardiner, 2012). This has resulted in devices that enable the development of ubiquitous or seamless learning environments that combine real-world and virtual resources. As a result, many educational researchers are exploring the potential for mobile technologies to enhance student learning, with mobile learning becoming one of the fastest growing areas within the field of ICTs in education (Pegrum, Oakley \& Faulkner, 2013).

If mobile technologies are to be effectively used for education delivery, a key question becomes how do we best use mobile technologies for teaching and learning? In addressing this, the first step is to explore how students are already using mobile technologies to support their learning. The research presented in this paper investigates the extent to which students currently have access to mobile technologies and whether they are using these to support their learning. This research progresses previous work conducted into student ownership of mobile devices (e.g. Oliver \& Goerke, 2007; McNeill, Diao, Gosper, 2011), by taking into account the rapid evolution of these technologies and shift in relative popularity of different devices, with smart phones and tablets dominating the market in more recent times. These devices have greater functionality and enable interactivity, thereby enhancing their potential affordances for both formal and informal learning.

The data collected for this research will be used to inform the next phase of this research project which is to develop a Mobile Learning Evaluation Framework (MLEF). The MLEF project is part of an Australian Government-funded Collaborative Research Network program led by the University of Southern Queensland (USQ) with the Australian National University (ANU) and the University of South Australia (UniSA). Researchers from a range of disciplines at these three universities are working together to develop a framework that will support institutional leaders and educators in higher education institutions with providing sustainable mobile learning opportunities to students. As illustrated in Figure 1, the framework is being developed across four levels within the higher education environment: 1 ) pedagogical (from the student perspective), 2) pedagogical (from the teacher perspective), 3) technical and 4) organisational (Murphy \& Farley, 2012). The trends, expectations and challenges experienced by stakeholders at each of these levels will be explored prior to the development of the framework. The data obtained during this study will be used to inform the second level of the framework. 


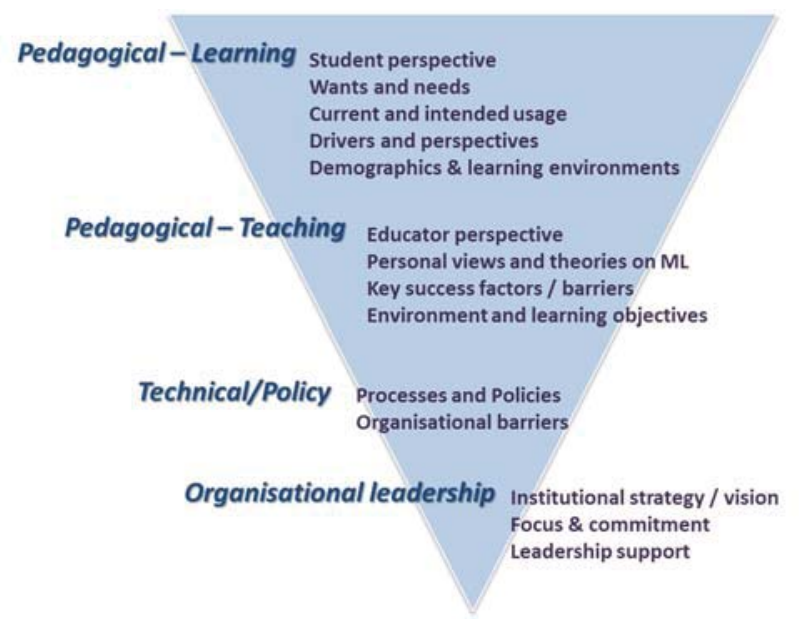

Figure 1: Four levels forming the foundation of the Mobile Learning Evaluation Framework (adapted from Murphy \& Farley, 2012)

\section{LITERATURE REVIEW}

Over the past ten years, a number of pilot studies have been conducted across a number of sectors to investigate the impact of mobile technologies on learning and teaching (e.g. Elias, 2011; Wong, 2012). One of the most consistent conclusions of these studies is that there remain a number of barriers that influence the adoption of mobile learning initiatives, both at an institutional and at a user level. Higher education institutions are cautious about investing in programs to provide students with mobile devices for learning, due to the rapidly changing nature of mobile technologies (Alrasheedi \& Capretz, 2013). Bring Your Own Device (BYOD) refers to the use of a student's own mobile technologies for learning and has been identified as a viable and cost-effective alternative to institutions supplying technologies for learning. It brings the added advantage of individuals being more comfortable and competent in using their own devices, therefore enhancing the potential for mobile learning adoption (Shim, Mittleman, Welke, French \& Guo, 2013). A thorough understanding of how students are already using their mobile devices to support learning could lead to the more effective and sustainable deployment of mobile learning initiatives across the higher education sector. Though ICT infrastructure, staff and student culture, levels of technical support, appropriate skillsets of staff and the ability to adjust pedagogical approaches to teaching and learning are important considerations when planning for the deployment of learning technologies, the student voice is also important and is frequently overlooked (Gosper, Woo, Muir, Dudley, \& Nakazawa, 2007). This research seeks to address this deficiency but placing emphasis on the student voice.

In 2005 and again in 2007, Oliver and Goerke surveyed some 413 and 290 undergraduate students respectively at an Australian university to determine their levels of mobile device ownership. In both cohorts, just under half of the students owned laptop computers. Interestingly in 2005, some 8 percent of students owned 'handheld computers', elsewhere described as PDAs. By the time of the next survey, this percentage had decreased slightly. Mobile phones were the most popular devices with nearly 97 percent of both cohorts owning them. Even though the Apple iPhone was released in 2007 and smart phones were becoming more visible in the marketplace, no distinction was made in the survey between feature phones and smart phones. Tablets were absent from the technology landscape with MP3 players and iPods being the only other technologies investigated. Ownership levels were reasonably high with 40 percent of students owning one in 2005, jumping to some 70 percent in 2007 (Oliver \& Goercke, 
2007). Though the authors did not specifically investigate whether or not students used their devices to support their learning, they did determine that students did use them for instant messaging (17.7 percent in $2005,12.0$ percent in 2007), accessing blogs (79.3 percent and 70.2 percent), and listening to podcasts (93.4 percent and 78.5 percent) (Oliver \& Goercke, 2007).

A study conducted by Kennedy, Judd, Churchward, Gray, and Krause in 2008 questioned the widely held assumption that students had sufficient access to technology and digital literacy levels to maximise their learning using technology. The majority of students in this study had unrestricted access to mobile phones (96 percent), desktop computers (90 percent), MP3 players (69 percent) and laptop computers (63 percent). Learning activities were mostly undertaken on desktop or laptop computers, with mobile phones reserved for voice calls and text messages. Again, no distinction was made between smartphones and feature phones. A more recent study found that student ownership of laptop computers had increased with most in the sample owning a laptop computer. (McNeill \& Diao, 2011). Interestingly, these students left their laptop computers at home rather than bring them to university due to the weight of the devices. Also, though most students had phones that connected to the internet, only one student had access to a smartphone and that was owned by a family member. The low levels of smartphone ownership were attributed to the high cost of purchasing and using the devices. Most students only used the basic functions of mobile phones including making phone calls and sending text messages with few accessing the internet.

Kobus, Rietveld and van Ommeren (2013) surveyed 3132 students from a Dutch university in The Netherlands in November, 2011. Their study investigated student ownership and on-campus use of laptops, tablets and smartphones and found that at that stage, only 11 percent of students owned or shared a tablet computer yet 68 percent owned a smartphone. Their research explored attitudes towards making laptop computers mandatory for use at university and found that 87 percent of students found laptop computers were too cumbersome to carry, supporting McNeill and Diao's (2011) conclusions. While these studies provide important insights into the uptake of mobile devices by university students, there remains a need to obtain information that is both applicable to the Australian higher education context and is up-to-date with respect to recent rapid advances in mobile technology. Further, there was very little research conducted into how students used mobile technologies to support their learning. This research seeks to address these issues.

\section{RESEARCH METHOD}

A quantitative survey was designed in April 2013 consisting of 28 closed and one open form question. It was divided into four sections: 1) student demographics; 2) the availability and quality of internet access; 3) ownership and access to mobile devices; and 4) usage of mobile devices to support learning. Participants were asked about their access and use of both mobile and tethered technologies such as desktop and laptop computers to enable comparison. The research instrument was initially piloted on a small sample of students and a few minor revisions were made. Two additional closed questions about the types of operating systems on tablets and smartphones were included in the revised survey instrument. The survey was administered using the online survey tool, Qualtrics. Questions about the learning activities engaged in by students were filtered according to the devices that students either owned or had the use of. This ensured that students only completed questions about technologies that they owned or actively used. The survey was piloted during March and April 2013. Course examiners from 13 online courses at USQ disseminated the link to their students for the pilot. Four of USQ's five faculties were represented: the faculties of Sciences, Business and Law, Arts and the Faculty of Education. Students were invited via email or via course discussion forums to participate. After refinement of the survey, a link was placed on the university announcement portal and was available to students during June and July 2013. Participation was voluntary and no incentives were offered to students. 
A total of 186 potential participants accessed the online survey and after removal of unusable responses, a sample of 100 participants was retained. Of the total sample, 37 completed responses were obtained during the survey pilot and 63 during the second data collection stage. The majority of the sample represented Australian residents (87 percent) and the remainder were international students (13 percent). Both on-campus (53 percent) and distance students (46 percent) were equally represented. Undergraduate students made up 78 percent of the sample and 22 percent were postgraduate students. A third of the sample consisted of first year students ( 35 percent). The sample consisted of more female (63 percent) than male (37 percent) participants and the age of students ranged from 17 to 61 with a mean age of $33(\mathrm{SD}=10.53)$. Furthermore, most of the participants were employed in addition to studying (63 percent), working a minimum of 4 hours and a maximum of 80 hours a week $(M=26$, $\mathrm{SD}=18.52)$.

\section{RESEARCH FINDINGS}

\section{Ownership and use of mobile technologies for learning purposes}

Survey participants were presented with a list of mobile technologies and asked whether they owned the device, had access to the device or neither owned nor had access to the device. Later, students were asked questions about how they used the devices they owned or had access to. Figure 2 indicates student ownership of mobile and tethered computing technologies. As illustrated, 87 percent owned and 8 percent used a smartphone, similarly 88 percent owned a laptop and 6 percent used one. Half of the participants owned (49 percent) or used (7 percent) an MP3 player; slightly fewer than half owned (46 percent) a tablet computer. An additional 21 percent of students used tablet computers resulting in a total of 67 percent of students having a tablet device at their disposal. Ownership of eBook readers (17 percent), netbook computers (15 percent) and feature phones (21 percent) was less common.

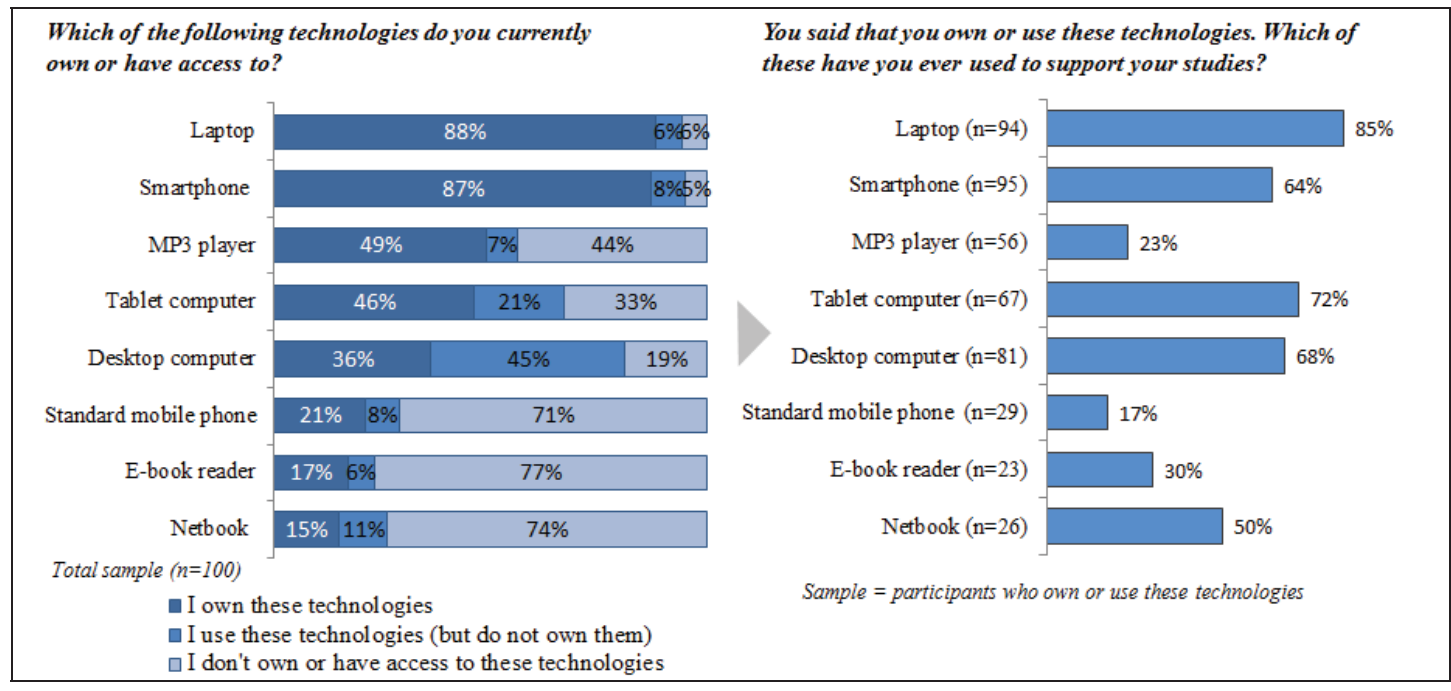

Figure 2: Ownership or access to mobile technologies

Further analysis revealed that students owned or used on average five (SD $=1.28$ ) of the mobile technologies on the list, and the minimum number of technologies owned by each student was two. Half of students who owned a smartphone (45, 52 percent) also owned a tablet computer. The four students who did not own or use a smartphone all had a feature phone and one had a tablet computer. Of the six students who did not own or use a laptop, all had a desktop computer and three had a netbook, two had a tablet computer and all had a smartphone. During the second data collection stage, a question 
was added to ask about the type of operating system participants had on their smartphones or tablet computers. Students who owned smartphones either had Apple iOS operating systems (35, 58 percent) or Android systems (21, 35 percent). Three students owned a phone with a Windows operating system (5 percent). Those who owned tablet computers mostly had iOS operating systems, i.e. they owned iPads (25, 56 percent), 24 percent (11) had Windows operating systems and 20 percent (9) had Android systems.

Participants were requested to indicate which of the technologies they owned or used, were used to support their learning. They were informed that this could refer to activities including accessing course materials, participating in discussion forums, communicating with other students or lecturers, or searching for information for their studies. Unsurprisingly, the dominant technology used to support learning was the laptop computer with 85 percent of respondents using them for this purpose. Tablet computers (72 percent) and smartphones (64 percent) were also used extensively by students to support their learning. Technologies such as MP3 players (23 percent), eBook readers (30 percent) and feature phones (17 percent) were used less often for learning purposes. Half of the students who owned netbook computers (50 percent) used them to support their learning. This suggests that lecturers could consider incorporating mobile learning initiatives into learning settings without potentially disadvantaging students without mobile technologies as most, if not all students own or have access to one or more mobile device. Furthermore, as smartphones or tablet computers are favoured by students as tools to support learning, there is scope to incorporate more sophisticated learning activities within classroom environments. These may include quizzes and polls which enable students to engage interactively with the learning content and the lecturer.

\section{Frequency and location of use of mobile technologies for learning}

All participants who owned or used each device were asked how frequently they used them to support their learning activities (See Figure 3). Laptop computers were used most frequently by students to support learning activities with 77 percent using them at least daily. Smartphones were the second most frequently used device with 52 percent using them on a daily basis to support learning, just surpassing the desktop computer (47 percent). Only some 42 percent of tablet computer owners were using them on a daily basis to support their learning, although a further 26 percent were using them for this purpose a few times a week. This suggests that tablet computers are being used more frequently than desktops computers over a period of a week. 


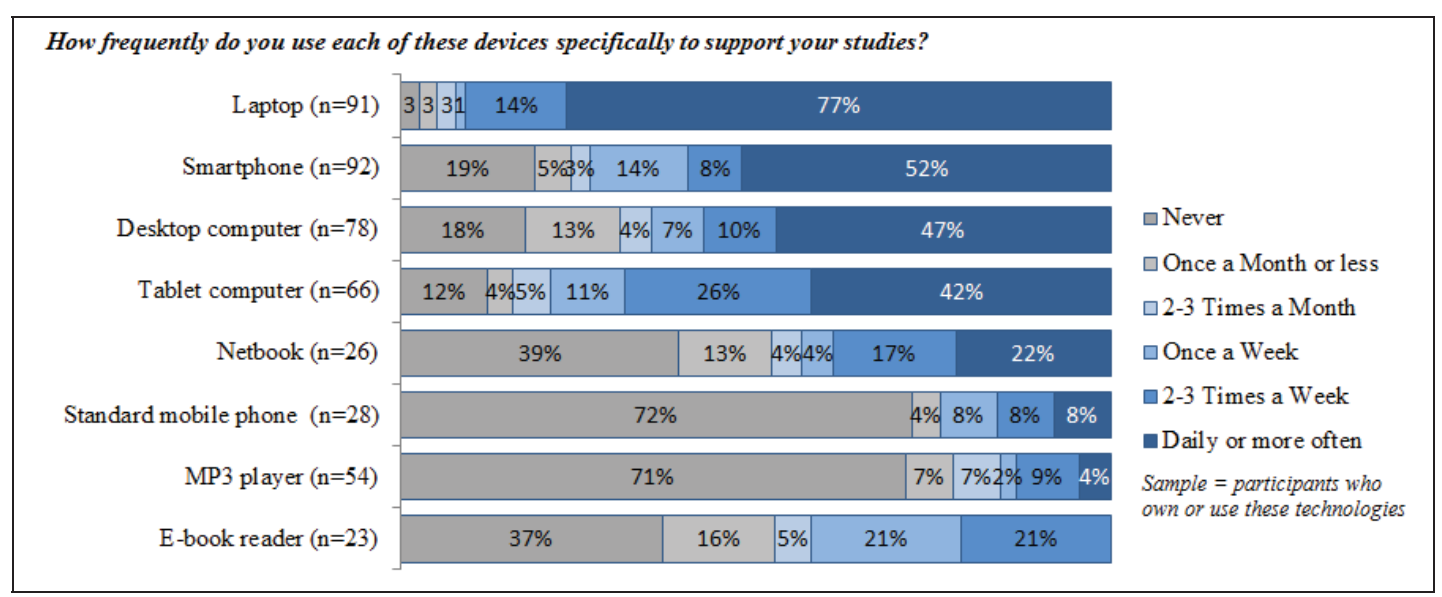

Figure 3: Frequency of use of mobile technologies for learning

There is some debate in the literature (Sharples, Taylor, \& Vavoula, 2005) as to whether students really do learn while physically moving between places. To explore this issue, participants were asked to indicate on a range of options, all of the locations where they used each of the technologies they owned or used specifically for learning. They were also encouraged to enter other locations if the location was not otherwise listed. The desktop computer was excluded in the analysis of the results as it is not mobile and the feature phone was excluded due to the low number of students who used this device for learning. Figure 4 shows that the home is the primary location for use of larger as well as easily portable mobile technologies such as smartphones (81 percent), eBook readers (82 percent) and tablet computers (82 percent). Although a surprisingly large proportion of students use smartphones (66 percent) and tablet computers at university (57 percent). Netbook computers (57 percent) are also more likely to be used at university than laptop computers (47 percent), most probably due to their size. 


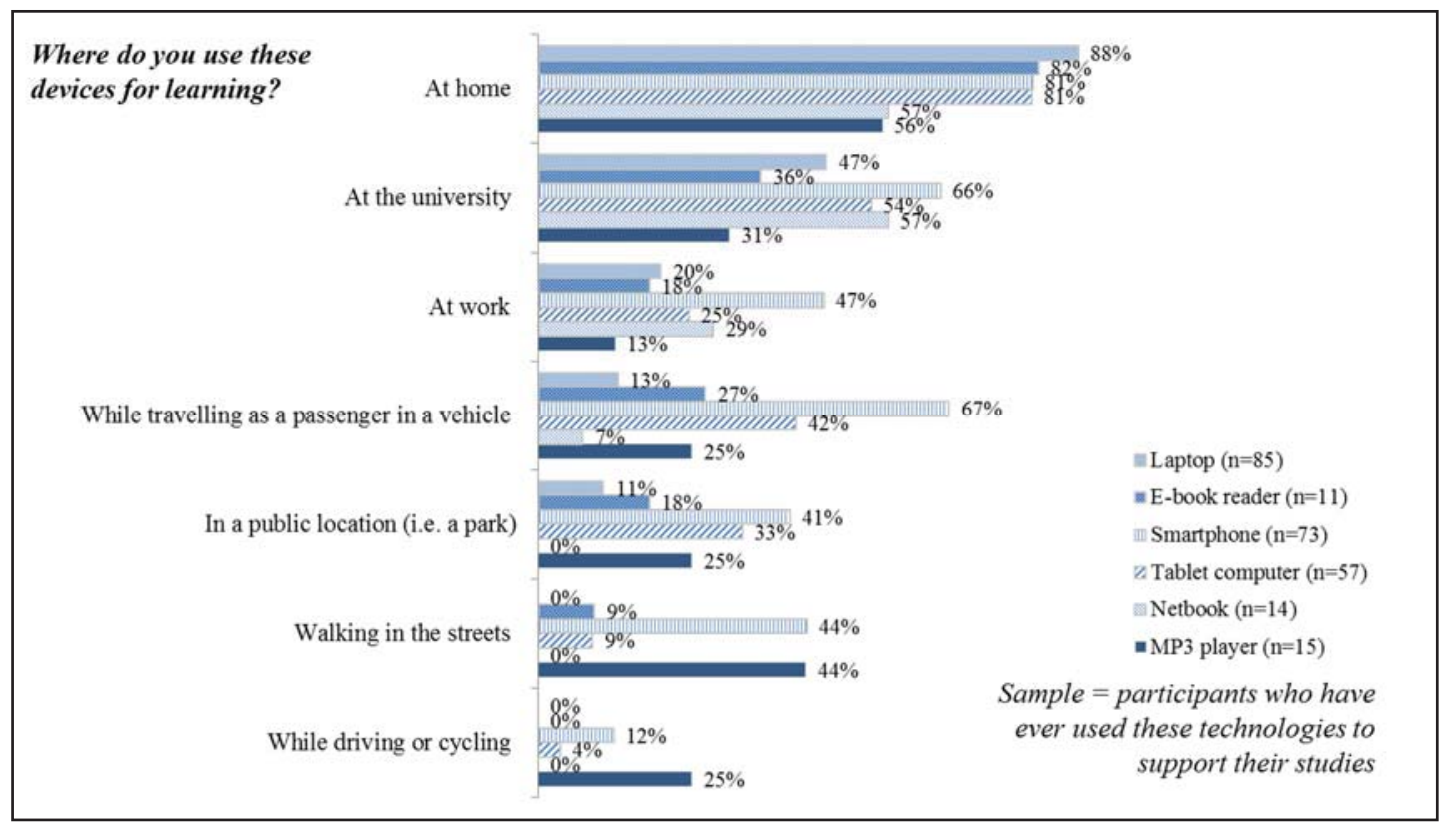

Figure 4: Use of mobile technologies for learning: by location

A large number of students are engaging in learning activities using their mobile technologies in locations other than at home or at university. A majority (67 percent) are using their smartphones to learn while travelling as a passenger in a vehicle, and 42 percent are using their tablet computers in this context. Smartphones are also being used extensively in other non-traditional locations for learning activities such as at work (47 percent), while walking (44 percent) and in public locations such as parks (41 percent). MP3 players are popular for learning while walking (44 percent). Additional open comments provided by students included locations such as on holiday or on work trips away from home, in transit between daily activities such as waiting in a doctor's office, at a child's school or sports event or at a friend's house. A comment from a participant which signifies the transitory nature of mobile learning was "everywhere, it's attached to me." These findings indicate that students do take advantage of physical mobility between locations as well as locations outside designated study spaces to engage in learning. Therefore lecturers who provide students with podcasts, video recordings or other multimedia content that can be downloaded and accessed from a mobile device are well placed to capture the attention of students seeking to engage with their studies outside of formal study locations and times.

\section{Using mobile devices to support learning}

Very few previous studies have attempted to discern the type of learning activities that students use mobile technologies for, particularly smartphones and tablet devices. To this end, students were provided with a list of potential learning activities and requested to indicate which they conducted on each of the mobile technologies that they owned or used. They were also provided with an open entry field to describe additional activities not on the list. Students could also indicate if they did not participate in the activity. Unsurprisingly, laptop computers were used for the majority of learning activities, except for taking photos or videos (23 percent), which suggests that this is still the dominant technology used by most students for learning purposes. Desktop computers were used for fewer activities, and most students used desktop computers for accessing or reading course materials (57 
percent), searching the internet for course related information (57 percent), communicating using emails (52 percent), and accessing the university's LMS (51 percent). Tablet computers and smartphones were used for very different activities suggesting that students consider them to be useful for significantly different aspects of their study. Tablet computers were used by students mostly for engaging with their formal learning materials, for example course materials (63 percent) and course textbooks (50 percent), searching the internet (56 percent) and taking notes ( 55 percent). Smartphones were most likely to be used for interactive communication and engagement with peers and teachers through emails (62 percent), social media (59 percent) and information sharing (52 percent). Smartphones were also used extensively to take photos or videos to support learning (66 percent).

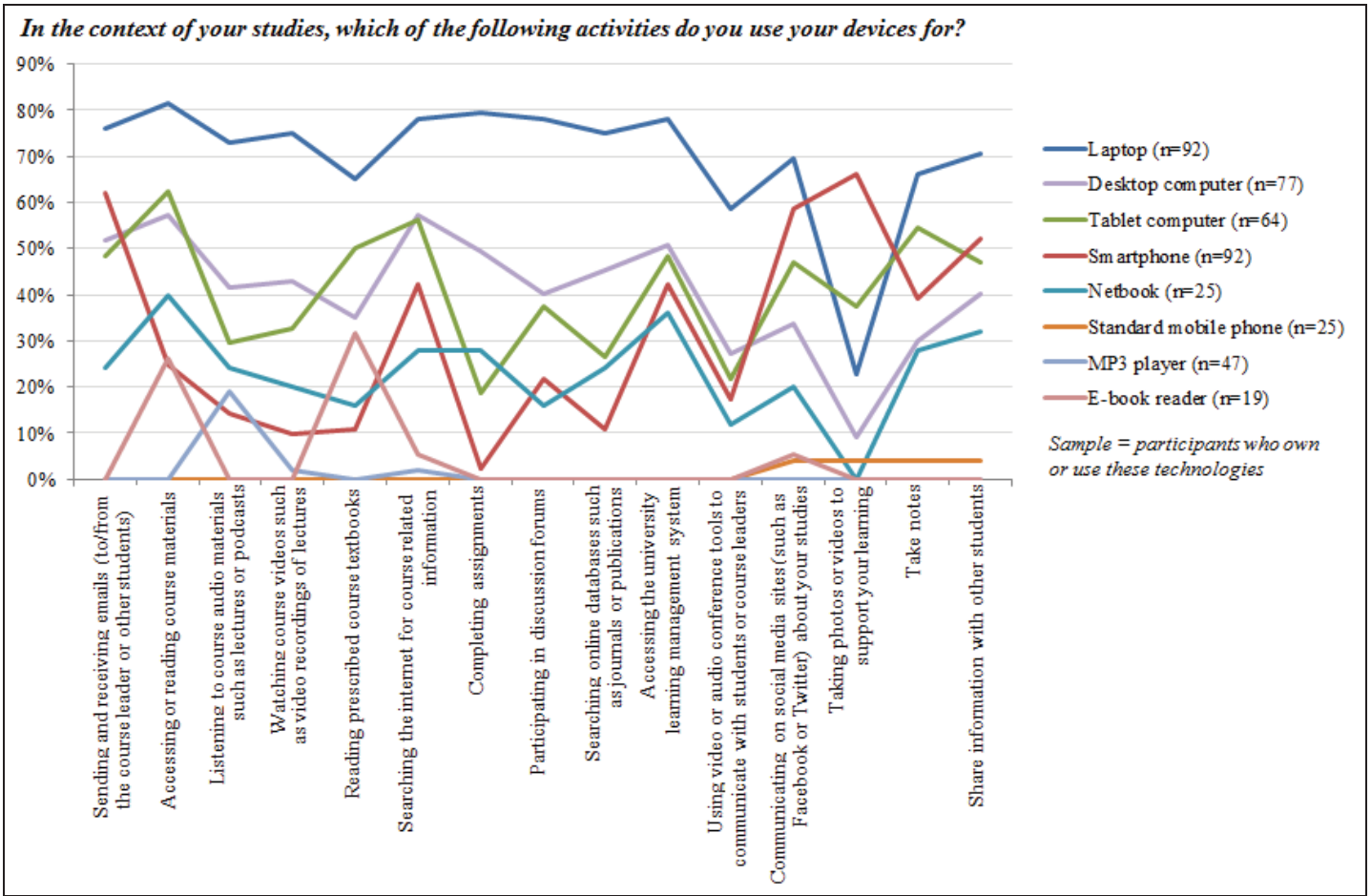

Figure 5: Frequency of learning activities undertaken with mobile technologies

Figure 5 (detailed figures provided in Table 1) provides some interesting insights into the extent to which students are using mobile technologies across a range of learning activities. Firstly, a feature phone is rarely used for the learning activities indicated, while the laptop is the most widely used device for learning. The laptop computer has logical troughs in use in some learning activities such as taking photos or videos. Smartphone usage provides some interesting insights with some learning activities such as sending and receiving email showing conducted often by students, whereas completing assignments was relatively uncommon. Tablets computers are sitting in the middle overall in terms of usage for the range of learning activities assessed in this study, again with some logical troughs and peaks in usage across the learning activities. These findings demonstrate that students are actively using their mobile technologies in specific ways to support their learning. As smartphones are used as devices to provide instant access to online information there is scope for these technologies to be used effectively to engage students more interactively during on-campus lectures. For example, students could be asked to search on a topic and provide feedback in small groups on information found rather than rely on the lecturer to transmit the information to them. For distance education students, learning 
content that is accessible on mobile technologies offer opportunities to take advantage brief moments between family and work responsibilities to engage in learning.

\begin{tabular}{|c|c|c|c|c|c|c|c|c|}
\hline Learning activities & Laptop & $\begin{array}{l}\text { Desktop } \\
\text { computer }\end{array}$ & $\begin{array}{c}\text { Tablet } \\
\text { computer }\end{array}$ & Smartphone & Netbook & $\begin{array}{l}\text { Standard } \\
\text { mobile } \\
\text { phone }\end{array}$ & $\begin{array}{l}\text { MP3 } \\
\text { player }\end{array}$ & $\begin{array}{l}\text { E-book } \\
\text { reader }\end{array}$ \\
\hline $\begin{array}{l}\text { Sending and receiving } \\
\text { emails (to/from the } \\
\text { course leader or other } \\
\text { students) }\end{array}$ & $75 \%$ & $53 \%$ & $48 \%$ & $61 \%$ & $24 \%$ & $0 \%$ & $0 \%$ & $0 \%$ \\
\hline $\begin{array}{l}\text { Accessing or reading } \\
\text { course materials }\end{array}$ & $81 \%$ & $56 \%$ & $60 \%$ & $26 \%$ & $40 \%$ & $0 \%$ & $0 \%$ & $26 \%$ \\
\hline $\begin{array}{l}\text { Listening to course } \\
\text { audio materials such } \\
\text { as lectures or podcasts }\end{array}$ & $72 \%$ & $39 \%$ & $28 \%$ & $14 \%$ & $24 \%$ & $0 \%$ & $19 \%$ & $0 \%$ \\
\hline $\begin{array}{l}\text { Watching course } \\
\text { videos such as video } \\
\text { recordings of lectures }\end{array}$ & $74 \%$ & $40 \%$ & $33 \%$ & $9 \%$ & $20 \%$ & $0 \%$ & $2 \%$ & $0 \%$ \\
\hline $\begin{array}{l}\text { Reading prescribed } \\
\text { course textbooks }\end{array}$ & $62 \%$ & $33 \%$ & $48 \%$ & $11 \%$ & $16 \%$ & $0 \%$ & $0 \%$ & $32 \%$ \\
\hline $\begin{array}{l}\text { Searching the internet } \\
\text { for course related } \\
\text { information }\end{array}$ & $76 \%$ & $54 \%$ & $57 \%$ & $41 \%$ & $28 \%$ & $0 \%$ & $2 \%$ & $5 \%$ \\
\hline $\begin{array}{l}\text { Completing } \\
\text { assignments }\end{array}$ & $78 \%$ & $47 \%$ & $18 \%$ & $2 \%$ & $28 \%$ & $0 \%$ & $0 \%$ & $0 \%$ \\
\hline $\begin{array}{l}\text { Participating in } \\
\text { discussion forums }\end{array}$ & $76 \%$ & $39 \%$ & $40 \%$ & $22 \%$ & $16 \%$ & $0 \%$ & $0 \%$ & $0 \%$ \\
\hline $\begin{array}{l}\text { Searching online } \\
\text { databases such as } \\
\text { journals or } \\
\text { publications }\end{array}$ & $73 \%$ & $43 \%$ & $28 \%$ & $12 \%$ & $24 \%$ & $0 \%$ & $0 \%$ & $0 \%$ \\
\hline $\begin{array}{l}\text { Accessing the } \\
\text { university Learning } \\
\text { Management System }\end{array}$ & $78 \%$ & $50 \%$ & $50 \%$ & $44 \%$ & $36 \%$ & $0 \%$ & $0 \%$ & $0 \%$ \\
\hline $\begin{array}{l}\text { Using video or audio } \\
\text { conference tools such } \\
\text { as Skype to } \\
\text { communicate with } \\
\text { fellow students or } \\
\text { course leaders }\end{array}$ & $60 \%$ & $26 \%$ & $18 \%$ & $15 \%$ & $12 \%$ & $0 \%$ & $0 \%$ & $0 \%$ \\
\hline $\begin{array}{l}\text { Communicating on } \\
\text { social media sites } \\
\text { (such as Facebook or } \\
\text { Twitter) about your } \\
\text { studies }\end{array}$ & $69 \%$ & $33 \%$ & $48 \%$ & $60 \%$ & $20 \%$ & $4 \%$ & $0 \%$ & $5 \%$ \\
\hline $\begin{array}{l}\text { Taking photos or } \\
\text { videos to support your } \\
\text { learning }\end{array}$ & $22 \%$ & $8 \%$ & $37 \%$ & $65 \%$ & $0 \%$ & $4 \%$ & $0 \%$ & $0 \%$ \\
\hline Take notes & $65 \%$ & $29 \%$ & $53 \%$ & $38 \%$ & $28 \%$ & $4 \%$ & $0 \%$ & $0 \%$ \\
\hline $\begin{array}{l}\text { Share information } \\
\text { with other students }\end{array}$ & $69 \%$ & $39 \%$ & $48 \%$ & $54 \%$ & $32 \%$ & $4 \%$ & $0 \%$ & $0 \%$ \\
\hline None of these & $12 \%$ & $31 \%$ & $20 \%$ & $21 \%$ & $52 \%$ & $88 \%$ & $81 \%$ & $58 \%$ \\
\hline
\end{tabular}

Table 1. Detailed frequencies of learning activities 


\section{Preferences and attitudes towards use of mobile technologies for learning}

Mobile learning can be described as the ability to learn anytime, anywhere (Traxler, 2005). To identify student preferences for and attitudes about mobile learning, participants were requested to respond to a series of statements on a five point scale from strongly agree (5) to strongly disagree (1). The overwhelming majority of students want to be able to learn anytime, anywhere $(\mathrm{M}=4.49, \mathrm{SD}=0.84)$ and would like to be able to use their mobile technologies to support their learning ( $M=4.47, S D=0.86$ ) (see Figure 6). The majority of students also indicated that they would like to use their mobile devices in formal learning environments such as in lectures or on excursions. Interestingly, a third of students disagree (12 percent) or strongly disagree (17 percent) that they would like to use their mobile devices in this context.

Further examination was undertaken using Pearson's Correlation to identify a potential reason for this finding. A strong negative correlation was found between this statement and the statement: "I would not want to use my mobile device in class or as part of my learning it is for staying in touch with my family and friends" ( $\mathrm{r}=-0.46, \mathrm{p}<.000, \mathrm{n}=93)$. Weaker negative correlations were also found for the perceived cost of this type of use: "using mobile devices for learning will be too expensive for me" ( $\mathrm{r}=-$ $0.37, \mathrm{p}<.000, \mathrm{n}=93$ ) and availability of sufficient internet access: "the internet access is too limited to effectively use mobile learning" ( $\mathrm{r}=-0.34, \mathrm{p}<.05, \mathrm{n}=93)$. This suggests that there is a cohort of students who are opposed to using mobile technologies in formal learning spaces due to the cost of using the devices, the limited availability of internet access in these locations, and the perception that mobile devices are personal objects only to be used for personal communications.

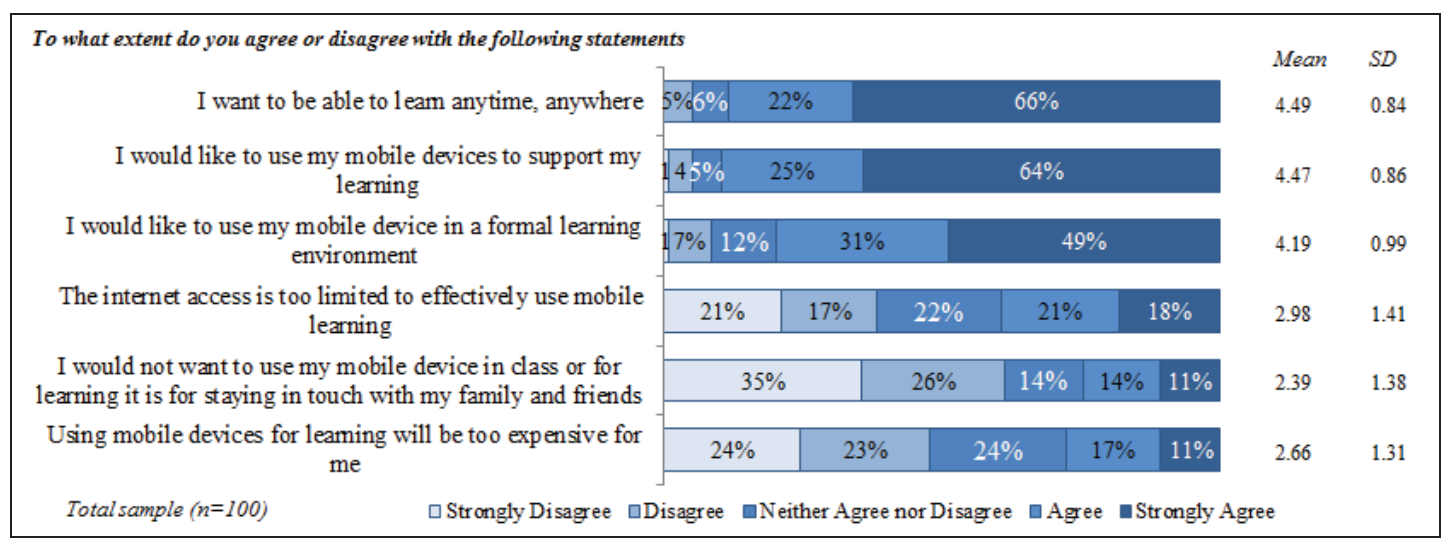

Figure 6: Attitudes towards using mobile for learning

Activities and learning materials designed for mobile technologies have not yet been effectively accommodated in the learning policies of the university where the research took place. Students were requested to indicate on a five point scale from very unlikely (1) to very likely (5), how likely they would be to use smartphones, tablet computers, e-book readers or MP3 players for learning if appropriate resources were available to support these devices. The results are presented graphically in Figure 7.

The reason for this question was to determine whether use of mobile technologies for learning purposes would increase with the improved availability of appropriate resources. The tablet computer proved to be the device that the most students would want to use to support learning with 76 percent indicating that they would be likely or very likely to use this technology for learning $(\mathrm{M}=4.10, \mathrm{SD}=1.35)$. Students indicated that smartphones were marginally less desirable for use as learning devices ( $M=3.87$, $\mathrm{SD}=1.35$ ). This suggests that tablet computer may yet surpass smartphones as the learning technology of choice for students in the near future. eBook readers $(\mathrm{M}=3.00, \mathrm{SD}=1.46)$ and $\mathrm{MP} 3$ players $(\mathrm{M}=2.63$, 
$\mathrm{SD}=1.39$ ) were considered to be beneficial for learning by fewer students, yet still appear to be preferred by some students to support learning.

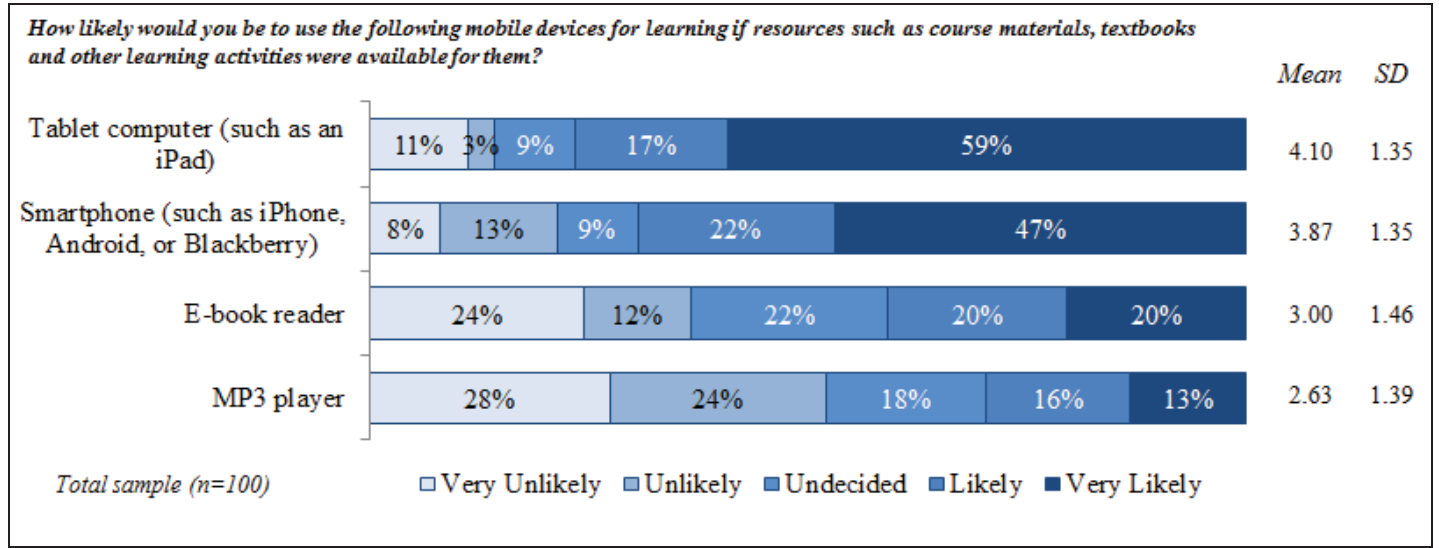

Figure 7: Preferences for using mobile technologies for learning

\section{DISCUSSION}

Findings from this research demonstrate that the adoption of mobile technologies, particularly smartphones and tablet computers, has increased considerably over the past three or four years. The results from this research markedly differ from the findings of previous studies which suggest that students' everyday use of technology centres on well-established technologies such as laptop computers and mobile phones without the internet (Gosper, Malfroy, \& McKenzie, 2013). In contrast, most students in the sample had access to smartphones and a large proportion had tablet computers, which is surprising as these technologies were only gained significant market share in early 2011.

Students are also using their mobile devices to support increasingly sophisticated learning activities previously only possible with computers. Up until relatively recently, desktop computers were the primary technology to support learning activities and mobile phones were considered to be tools for interpersonal communications through calls, text messages or emails (Ellis \& Newton, 2009). Students in this sample appear to have leveraged the greater functionality and connectivity of smartphones and tablet devices and are actively using these technologies to support their learning. The smartphone in particular is being used by students for collaborative activities such as sharing information and communicating through social media. This supports findings by Gikas and Grant (2013) who found that students with mobile devices in classrooms benefited extensively from the constant connectivity available to them and the ability to communicate with classmates and instructors. The results from this study demonstrate that students use tablet computers very differently to smartphones. Students appear to use tablet computers more as a transmissive technology to access course materials and the internet, rather than as a collaborative tool. This may simply be because students are still early adopters of tablet computers and may be unaware of the ways to use the devices to support greater collaboration and interactivity with peers and learning materials. The level of access students have to sophisticated devices, as well as the extensive use of these devices to support learning, clearly indicates that students would benefit from the provision of initiatives to support mobile learning both on-campus and at a distance.

This study shows that students engage with learning while they are on the move and in non-traditional learning locations as they go about their daily lives. One limitation of this study is that it is not possible to identify the exact nature of the mobile learning activities that students are engaged in. A series of online and on-campus focus groups are currently underway to gain greater insight into these trends. 
Data about the attitudes and preferences of students towards the ability to learn anytime, anywhere raises a few concerns when considering the piecemeal support of this kind of learning by institutions. The majority of students appear to want to be able to learn anytime, anywhere and prefer to use their mobile devices for informal learning. There appears to be some resistance to the use of these devices for formal learning purposes as a third of students are uncertain or opposed to the use of their own technologies within classrooms or on excursions. These findings have significant implications for institutions that wish to rely on BYOD policies to encourage greater interactivity during classroom sessions. The high correlation with statements that indicate concern about the cost implications of this type of use and the availability of internet access does suggest that some of these concerns could be rectified by ensuring students have adequate access to free on-campus internet. The potential for mobile technologies to enhance and enrich student learning also poses challenges for higher education institutions. If academics start to embrace the possibilities for enhancing and enriching student learning through well designed learning activities which are fit for purpose for the different types of mobile technologies, then this may also be a double edged sword. Students who don't have access to these mobile technologies and the accompanying connectivity may be severely disadvantaged in their learning.

\section{CONCLUSION}

This research was aimed at obtaining exploratory data about the ownership of mobile technologies among higher education students and their use of these technologies to support informal learning. The findings of this research clearly indicate that a range of mobile technologies which are fit for purpose for a range of learning activities, are being embraced by students. Laptops, smart phones and tablets devices appear to be dominant technologies being used by students for a range of learning activities. The use of these mobile technologies across these learning activities have logical troughs and peaks indicating that students are using these mobile technologies in a common sense and programmatic manner to best effect to support their learning. Furthermore our findings indicate that mobile technologies present both opportunities and challenges to academics and institutions to create learning activities which better utilise the multi-functionality of mobile technologies such as laptops, smart phones and tablets. But at the same time this also creates some dilemmas in that learning activities which are facilitated by mobile technologies may actually disadvantage students who don't have access to these technologies and connectivity. This study has the potential to support institutional planning by providing insights into the ways students are currently using technologies for learning and their attitudes preferences for future use.

\section{Next steps and future research directions}

It is a limitation of this study is that it only presents findings from a very early exploratory investigation of the use of mobile technologies for personal and professional use within the student cohort of a large distance education institution within regional Australia. As such, the study does not address the potential impact of specific mobile learning interventions on student learning outcomes. The survey developed for this research will soon be deployed with students at ANU and UniSA. This will increase the representativeness of the results and gain a more complete picture of mobile device ownership and use to support learning by Australian students in a range of institutional contexts (Go8 versus Regional Universities Network, distance versus face-to-face). The survey has also been deployed in a number of Asian countries including Malaysia, Thailand, Vietnam and China to see if identified trends are consistent across other Asian countries. Focus groups are currently underway with students at USQ, ANU and UniSA to further tease out how students are using mobile devices to support their learning, and the personal and institutional barriers to use they face. The resulting data from these studies as well as the focus groups conducted at the three universities will be used to develop a model for the pedagogical learning level of the MLEF (see figure 1). A survey will be developed to test this model 
and will be disseminated to the three universities involved in the study as well as other Australian and international higher education institutions. The aim of the final MLEF will be to provide institutions with a model representative of the mobile learning trends and preferences of students across a range of cultures and disciplines. The data from these studies will also be made available for use as benchmarking data for other organisations.

\section{REFERENCES}

Alrasheedi, M. and Capretz. L.F. 2013. "Can mobile learning maturity be measured? A preliminary work," Proceedings of the Canadian Engineering Education Association. Retrieved 2 August, 2013, from http://library.queensu.ca/ojs/index.php/PCEEA/article/view/4805

Ally, M., and Gardiner, M. 2012. "Application and device characteristics as drivers for smart mobile device adoption and productivity," International Journal of Organisational Behaviour (17: 4), September-December, pp 35-47.

Elias, T. 2011. "Universal Instructional Design Principles for M-learning," International Review of Research in Open and Distance Learning (12:2), February, pp 143-156.

Ellis, A. and Newton, D. 2009. "First year university students' access, usage and expectations of technology: An Australian pilot study" In World Conference on E-Learning in Corporate, Government, Healthcare, and Higher Education (2009:1), Vancouver, Canada, pp. 2539-2546.

Gikas, J. and Grant, M. 2013. "Mobile computing devices in higher education: Student perspectives on learning with cellphones, smartphones \& social media," The Internet and Higher Education, (19), October, pp 18-26.

Gosper, M., Malfroy, J., and McKenzie, J. 2013. "Students' Experiences and Expectations of Technologies: An Australian Study Designed to Inform Planning and Development Decisions,” Australasian Journal of Educational Technology (29:2), pp 268-82.

Gosper, M., Woo, K., Muir, H., Dudley, C., and Nakazawa, K. 2007. "Selecting Ict-Based Solutions for Quality Learning and Sustainable Practice," Australasian Journal of Educational Technology (23:2), May, pp 227-247.

Kennedy, G., Judd, T. S., Churchward, A., Gray, K. and Krause, K. 2008. "First year students' experiences with technology: Are they really digital natives?," Australasian Journal of Educational Technology (24:1), November, pp 108-122.

Kobus, M.B.W., Rietveld, P., and van Ommeren, J.N. 2013. "Ownership versus on-campus use of mobile IT devices by university students," Computers \& Education (68), October, 29-41.

Matias, A., and Wolf, D.F. 2013. "Engaging Students in Online Courses Through the Use of Mobile Technology," in Increasing Student Engagement and Retention Using Mobile Applications: Smartphones, Skype and Texting Technologies (Cutting-edge Technologies in Higher Education, Volume 6), L.A. Wankel, and P. Blessinger (eds.), Emerald Group Publishing Limited, pp 115-142.

McNeill M., \& Diao, M.M. 2011. MQ Student Uses Of Technologies For Learning: An Ethnographic $\begin{array}{lllll}\text { Study. } & \text { Retrieved } & 2 & \text { August, } & \text { 2013, from }\end{array}$ http://www.mq.edu.au/ltc/altc/student_it_experience/index.htm

McNeill, M., Diao, M.M., and Gosper, M., (2011) "Student uses of technology in learning: two lenses", Interactive Technology and Smart Education (8:1), pp.5 - 17.

Murphy, A., \& Farley, H. (2012). "Development of a framework for evaluating the impact and sustainability of mobile learning initiatives in higher education," in Proceedings of the ASCILITE - Australian Society for Computers in Learning in Tertiary Education Annual Conference, M. Brown, M. Hartnett and T. Stewart (eds.), Wellington, NZ, November, pp 678680 . 
Oliver, B., and Goerke, V. 2007. “Australian Undergraduates' Use and Ownership of Emerging Technologies: Implications and Opportunities for Creating Engaging Learning Experiences for the Net Generation," Australasian Journal of Educational Technology (23:2), May, pp 171-86.

Pegrum, M., Oakley, G., and Faulkner, R. 2013. "Schools going mobile: A study of the adoption of mobile handheld technologies in Western Australian independent schools," Australasian Journal of Educational Technology (29:1), pp 66-81.

Peters, K. 2009. "M-Learning: Positioning Educators for a Mobile, Connected Future", in Mobile learning: Transforming the delivery of education and training. M. Ally (ed.), Edmonton, Canada: Athabasca University Press, pp 113-134.

Sharples, M., Taylor, J., \& Vavoula, G. 2005. “Towards a Theory of Mobile Learning”, Proceedings of mLearn2005- 4th World Conference on mLearning, Cape Town, South Africa, October. Retrieved 2 August, 2013, from http://www.mlearn.org.za/CD/papers/Sharples\%20Theory\%20of\%20Mobile.pdf

Shim, J. P., Mittleman, D., Welke, R., French, A. M., and Guo, J. C. 2013. "Bring Your Own Device (BYOD): Current Status, Issues, and Future Directions," in Proceedings of the 19th Americas Conference on Information Systems (AMCIS). Retrieved 2 August, 2013, from http://aisel.aisnet.org/cgi/viewcontent.cgi?article=1296\&context=amcis2013.

Traxler, J. and Kukulska-Hulme, A. 2005. "Mobile Learning in Developing Countries", in Knowledge Series: A topical, start-up guide to distance education practice and delivery, Vancouver, BC: Commonwealth of Learning. Retrieved 2 August, 2013, from http://www.academia.edu/2810630/Mobile_learning_in_developing_countries

Wong, W. 2012. "Tools of the Trade: How Mobile Learning Devices Are Changing the Face of Higher Education," Community College Journal (82:5), Apr-May, pp 54-61.

\section{ACKNOWLEDGEMENTS}

This project is supported through the Australian Government's Collaborative Research Networks (CRN) program.

An earlier version of this paper was presented at the Australasian Conference on Information Systems (ACIS) 2013 in Melbourne, Australia. 